\title{
Article
}

\section{Variation in body composition in professional soccer players: inter- and intra-seasonal changes and the effects of exposure time and player position}

Carling, C., and Orhant, E.

Available at http://clok.uclan.ac.uk/12336/

Carling, C., ORCID: 0000-0002-7456-3493 and Orhant, E. (2010) Variation in body composition in professional soccer players: inter- and intra-seasonal changes and the effects of exposure time and player position. Journal of

Strength and Conditioning Research, 24 (5). pp. 1332-1339. ISSN 1064-8011

It is advisable to refer to the publisher's version if you intend to cite from the work. http://dx.doi.org/10.1519/JSC.0b013e3181cc6154.

For more information about UCLan's research in this area go to http://www.uclan.ac.uk/researchgroups/ and search for <name of research Group>.

For information about Research generally at UCLan please go to http://www.uclan.ac.uk/research/

All outputs in CLoK are protected by Intellectual Property Rights law, including Copyright law. Copyright, IPR and Moral Rights for the works on this site are retained by the individual authors and/or other copyright owners. Terms and conditions for use of this material are defined in the policies page. 
This is a pre-proof corrected manuscript, as accepted for publication, of an article

published by Lippincott Williams \& Wilkins in Journal of Strength and Conditioning

Research i May 2010, available online: http://ovidsp.tx.ovid.com/sp-

3.16.0a/ovidweb.cgi?T=JS\&PAGE=fulltext $\& D=$ ovft $\& A N=00124278-201005000-$

00025\&NEWS $=$ N\&CSC $=$ Y $\&$ CHANNEL $=$ PubMed

PLEASE REFER TO THE PUBLISHED VERSION FOR CITING PURPOSES

Variation in body composition in professional soccer players: inter- and intra-seasonal changes and the effects of exposure time and player position

Running head: variations in body composition

Christopher Carling, , ${ }^{1}$ Emmanuel Orhant,. ${ }^{2}$

${ }^{1}$ Ecole des Métiers du Sport Professionnel, Lille Olympique Sporting Club, Centre de Formation, Domain de Luchin, Camphin-en-Pévèle, 59780, France.

${ }^{2}$ Olympique Lyonnais Football Club, 350 avenue Jean Jaurès, 69361 Lyon, Cedex 07, France.

Corresponding Author: Christopher Carling, Ecole des Métiers du Sport Professionnel, Lille Olympique Sporting Club, Centre de Formation, Domain de Luchin, Camphin-enPévèle, 59780, France. Tel: +331 489107 93. E-mail: chris.carling@free.fr 


\section{ABSTRACT}

The aim of this study was to examine variations in measures of body composition in elite soccer players. Skinfolds and measures of body mass (BM) recorded on a monthly basis across an entire competitive season in a group of senior professional players $(\mathrm{N}=26)$ were used to estimate body fat $(\% \mathrm{BF})$ and provide fat-free body mass values (FFBM). Mean values in players were compared between six specific positional roles (goalkeepers, central and lateral defenders/midfielders and centre-forwards). In-season variations in measures were studied by comparing values at 5 separate points across the season. The effects of positional group (goalkeepers, defenders, midfielders and forwards) and exposure time to play (participation time in training and matches) in relation to in-season variations were also examined. To investigate inter-seasonal changes, repeated measures were taken in players $(\mathrm{N}=9)$ over three consecutive seasons. In relation to positional role, a difference in average $\% \mathrm{BF}$ and $\mathrm{BM}$ values was observed $(\mathrm{p}<0.001)$ with substantial differences observed in goalkeepers, lateral midfielders and forwards. Across all players, there were significant in-season variations in \% BF (between start- and mid-season and mid- and end-season, $\mathrm{p}<0.001$ ) and FFBM (between start- and mid-season and start- and end-season, $\mathrm{p}<0.001)$ while BM remained unchanged. Further analysis of these fluctuations in $\%$ BF and FFBM at different points of the season showed that variations differed across the positional groups $(\mathrm{p}<0.01)$, especially in defenders and midfielders. In contrast, no association was observed between measures and exposure time and no differences were reported across seasons. Practitioners should consider individual positional role when interpreting mean body composition data. They should also take into account positional groups when in-season variations in body composition are identified. 
Key words: skinfolds, body fat, football, performance 


\section{INTRODUCTION}

Many factors are relevant in determining the success of a soccer player and the requirements for high-level play are multifactorial (27). Over recent years, researchers have identified certain anthropometric and fitness characteristics that predispose certain players towards success in soccer $(5,14,30)$. In addition, there are anthropometric and fitness predispositions for the different playing positions within soccer. Significant differences in a variety of anthropometric characteristics, most notably stature and body mass have previously been reported across soccer players suggesting that these variables denote a morphological optimization within soccer and that anthropometric measurement of players should therefore be an integral part of a performance profiling programme $(9,27)$.

The physical composition of the body (body fat, mass and fat-free mass) is also relevant in the preparation of players for competitive performance. It is an important component of fitness as excess adipose tissue acts as dead weight in common game activities such as running and jumping where body mass must be lifted repeatedly against gravity (25). It is also recognised that body fat levels affect energy expenditure, players' power to weight ratio, and acceleration capacity (12). The functional performance characteristics of soccer players are therefore influenced by differences in body size and composition (33). Consequently, observations obtained through the evaluation of athletic performance should take these factors into account. In addition, the physical composition of the body is influenced by training and the balance between energy intake and expenditure is therefore of interest to practitioners (4). In periods of inactivity such as the off-season, non-selection or when a player is injured, body composition may be adversely affected. 
The measurement of body composition in elite soccer players has received widespread attention especially with respect to playing positions and to the description of changes across the playing season. For example, research has shown variations in estimated body fat and body mass across playing positions with the highest values generally found in goalkeepers $(26,27)$. However, analysis of competitive performance suggests that training and fitness testing should be tailored specifically to individual positional role (e.g., separation between central and lateral midfielders) rather than simply differentiating between forward, midfield and defending positional groups as each positional role has its own unique physical demands (3). Surprisingly, this recommendation has not been followed in reports of body composition in soccer players.

Previous studies having examined the seasonal effects on body composition include investigations on professional English (7,10,36,37), Japanese (15), Spanish (6) Singapore (1) and Turkish (18) players. The results from these studies have reported significant changes at different points across the season although several investigations only provided measurements at the beginning and end of the season. This weakness is apparent as significant differences in body composition have been reported between the off-season, pre-season conditioning and competition periods in top-level Serbian players with variations closely associated with changes in functional performance (23). In addition, there are no studies of intra-season variations in body composition that have distinguished across the various playing positions and the effects of exposure time (time spent in training and competition) on measures is unknown. Finally, little information is available on season-to-season variations in body composition (35). 
In this study on variations in body composition in senior professional soccer players, several questions were addressed: First, do measures of body composition (estimated body fat, mass and fat-free mass) vary according to positional role: six positions rather than the basic division into four positional groups commonly used in other studies? Second, at which points of the season do variations in measures of body composition occur? Third, do fluctuations across the season vary between positional groups? Fourth, is exposure time in competition and training linked to variations in body composition? Finally, to what extent does body composition vary between seasons?

\section{METHODS}

\section{Experimental Approach to the Problem}

Body composition is a significant component of fitness for soccer and can significantly vary across positional groups and during the course of the season (26). To further current knowledge on variations in body composition in elite soccer players, skinfolds (to estimate body fat) and body mass measures were taken over a single season to determine whether mean body composition values differ according to the specific positional roles within the team. In addition, the effects of positional group and exposure time to play (player participation time in training and competition) on variations in body composition across the same season were investigated. Finally, to ascertain whether body composition varies between seasons, measures were compared over three consecutive seasons. 
A total of 30 senior professional soccer players mean age $24.4( \pm 4.1)$ years, height $182.1( \pm 5.8) \mathrm{cm}$ and weight $76.8( \pm 5.8) \mathrm{kg}$, who attended a French League 1 professional soccer club participated. Over the course of the present study, the club achieved three top-ten finishes in the League and also participated in the 2006-2007 UEFA Champions League tournament. On average, players trained five times per week and participated in up to 50 competitive matches per season. Body composition in players belonging to the first- and reserve-team squads combined was assessed as part of standard fitness testing over three entire seasons (2005-2006, 2006-2007 and 20072008).

All subjects received a clear explanation of the study, including the risks and benefits of participation, and written consent was obtained. The study was approved by the Independent Institutional Review Board of LOSC Football Club according to the Guidelines and Recommendations for European Ethics Committees by the European Forum for Good Clinical Practice (1997).

\section{Procedures}

All players underwent a battery of anthropometric and fitness tests at the beginning of the competitive season. Body composition measurements (skinfolds and body mass) were performed on fourteen occasions across each season between June and May. The measurements were performed at the start of the first conditioning period (June) and once every month until the end of the season. An extra measurement was made just before the mid-season break (end of December). Only players $(n=26)$ for whom full datasets were available were included in the final analysis. 
To ensure standardisation of test administration across the entire study period, testing was scheduled at the same time of day using the same apparatus. Body composition was assessed between 0800 and 1200 hours with the athletes presenting in a fasted state. All test procedures over the entire study period were undertaken by the same experienced physician specialised in sports medicine.

\section{Body composition}

Body composition measurements were obtained using portable measurement devices and standardised laboratory procedures. Calibrated precision weighing scales (Holtain, Instruments Ltd, Crymych, United Kingdom) were used to obtain body mass to the nearest $0.1 \mathrm{~kg}$ (32). Skinfold thicknesses provide an indication of fatness located in subcutaneous storage areas and can be used to monitor changes in peripheral fat stores over time (22). As this is the most accessible method for obtaining data on body composition in soccer players (26), skinfolds were measured at four sites using a Harpenden skinfold calliper (British Indicators Ltd, Luton, UK). The upscale pressure of the calliper was checked according to the manufacturer's specification, and was constant at $10 \mathrm{~g} / \mathrm{cm}^{2}(16)$. Measures were taken at the triceps, biceps, subscapular, and suprailiac on the participant's right side. Total body density was estimated from the sum of the skinfolds according to a linear regression equation as previously described by Durnin and Womersley (11) and converted to the percentage of body fat using Siri's formula (31). Fat-free mass values were obtained from the measures of estimated body fat and body mass.

Recording of exposure time 
A $\log$ of the participation time in training and matches for each month (including firstteam and reserve-team games) for the squad of professional players was kept by the same physician over the entire 2007-2008 season to investigate the relationship between body composition and exposure time to play.

Statistical Analyses

All results are reported as means and standard deviations (mean \pm SD) calculated by conventional procedures unless otherwise stated. All calculations were performed using Microsoft Excel and Statistica.

The intra-class correlation coefficients for test-retest reliability and typical errors of measurement were calculated for the sum of four skinfolds and body mass based on repeated measurements in 15 players. Values obtained for test-retest reliability and typical error of measurement were 0.97 and 0.99 and $3.2 \%$ and $0.2 \%$ respectively.

A one-way repeated-measures analysis of variance was used to examine changes in mean values for each squad of players over the course of the 2007/08 season and the Bonferroni adjustment was used for multiple comparisons. The same procedure was employed to examine inter-seasonal differences in data obtained in players who had participated over the three consecutive seasons (2005/06, 2006/07, 2007/08) and to investigate intra-seasonal values across the four positional groups during the 2007/08 season. One way analysis of variance was used to compare mean data between the six positional roles during the 2007/08 season. Follow-up univariate analyses using Bonferroni-corrected pair wise comparisons were used where appropriate. Cohen's effect size conventions (8) were used for small (0.25), medium (0.5) and large (0.8) 
comparative effects. The relationship between body composition measures and participation time in the 2006/07 season was examined using a Pearson Product Moment Correlation Matrix. The level of significance was set at $\mathrm{p}<0.05$.

\section{RESULTS}

Body composition according to positional role

To provide a detailed comparison of mean estimated body fat and mass values, participants were divided into sub-groups according to the individual positional role of each player. Six specific roles were included for analysis: goalkeepers, central and lateral defenders, central and lateral midfielders, and forwards. The mean of the measures obtained on each of the fourteen occasions was calculated. Analysis of variance demonstrated a significant difference in both estimated body fat and body mass across groups $(\mathrm{p}<0.001$, ES 1.0). The follow-up analyses revealed greater estimated body fat values in goalkeepers versus all other positions $(p<0.001)$, in lateral midfielders versus central midfielders and versus central and lateral defenders $(\mathrm{p}<0.001)$, and in forwards versus both central midfielders $(\mathrm{p}<0.01)$ and central defenders $(\mathrm{p}<0.01)$. Figure 1 presents estimated body fat according to playing position. The post hoc analyses on body mass demonstrated higher values in goalkeepers versus all other positions $(\mathrm{p}<0.001)$, in forwards versus all positions (except goalkeepers) $(\mathrm{p}<0.001)$, in central-midfielders versus lateral midfielders $(\mathrm{p}<0.001)$ and lateral defenders $(\mathrm{p}<0.001)$, and in central defenders versus lateral defenders $(\mathrm{p}<0.001)$ and lateral midfielders $(\mathrm{p}<0.001)$.

Insert Figure 1 about here. 
Intra-season variation in body composition

Table 1 presents body composition values (percent body fat, body mass, fat-free mass) across all participants. A significant difference was revealed by ANOVA in both estimated body fat $(\mathrm{p}<0.001$, ES 0.98) and fat-free weight $(\mathrm{p}<0.001$, ES 0.93$)$ across the five different points in the season. No difference was reported for body mass values $(\mathrm{p}=0.071$, ES 0.35$)$. The post hoc tests on estimated body fat demonstrated a reduction from pre- to mid-season values $(\mathrm{p}<0.01)$ and an increase from mid- to end-season values $(\mathrm{p}<0.01)$. Post hoc analyses on fat-free mass demonstrated a significant increase from pre- to mid-season values $(\mathrm{p}<0.001)$ and a significant increase from pre- to endseason values $(\mathrm{p}<0.01)$.

Further investigation of the dataset showed that the largest loss in estimated body fat $(-0.3 \%)$ was between October-November whereas the largest loss in body mass $(-0.3 \mathrm{~kg})$ and in fat-free mass $(-0.5 \mathrm{~kg})$ was between January-February and May-June respectively. The largest gain in estimated body fat $(+0.3 \%)$ was between May-June whereas the largest gain in body mass $(+0.6 \mathrm{~kg})$ and fat-free mass $(+0.5 \mathrm{~kg})$ was between February-March.

Insert Table 1 about here.

Intra-season variation in body composition according to positional group The measures of body composition recorded at five separate points of the season (preseason, end of pre-season training, mid-season, end of mid-season break and end of season) were investigated across four basic positional groups (goalkeepers, defenders, midfielders and forwards) (Table 1). A significant difference in estimated body fat 
$(\mathrm{p}=0.002, \mathrm{ES}=0.93)$ and fat-free mass $(\mathrm{p}=0.009, \mathrm{ES}=0.92)$ was observed in midfielders across the season. A significant difference in fat-free mass was also observed in defenders $(\mathrm{p}=0.008$, ES 0.78). Post hoc analyses revealed an increase in estimated body fat from pre- to mid-season $(\mathrm{p}<0.01)$ and mid- to end-season $(\mathrm{p}<0.01)$ in midfielders and an increase in fat-free mass from pre- to end-season $(\mathrm{p}<0.01)$ in defenders. In goalkeepers, statistical significance was also reached ( $\mathrm{p}=0.042$, ES 0.53) but this was not lower than the adjusted alpha level after Bonferroni's correction. No intra-seasonal differences in body mass were reported for any of the playing positions.

Inter-season variation in body composition

Analysis of variations over three seasons in 9 players belonging to the professional squad was undertaken using the mean values of percent body fat, mass and fat-free mass from each season. Comparisons were made on the pre-season and end-season values for each season. The difference between these two time points (end-season minus preseason values) was also compared between seasons. Statistical significance was reached for the difference over the three seasons between pre- and end-season fat-free mass values $(\mathrm{p}=0.043$, ES 0.52) and in pre-season mass values ( $\mathrm{p}=0.032$, ES 0.6) but these were not lower than the adjusted alpha level after Bonferroni's correction. In addition, the difference between pre- and end-season percent body fat $(\mathrm{p}=0.069$, ES 0.41) approached significance. Figure 2 presents the mean pre- and end-season percent body fat values over the three seasons.

Insert Figure 2 about here.

Relationship between participation time and variation in body composition 
No significant association was observed between participation time (combined training and match exposure time) and estimated body fat $(r=0.12, p>0.05)$, body mass $(r=0.48$, $\mathrm{p}>0.05)$ and fat-free mass $(\mathrm{r}=0.42, \mathrm{p}>0.05)$ values over the course of the season.

\section{DISCUSSION}

The purpose of this study was to investigate several factors that could explain variations in body composition in a professional soccer team. The major findings were that body composition in a group of professional soccer players varied substantially according to the specific positional roles of players and that there were significant variations across the season with changes dependant on positional group but not exposure time. No significant inter-seasonal differences were observed.

In elite soccer, previous research has shown that percent body fat and body mass values differ greatly between goalkeepers and the other outfield positions (26). A report on high-level youth players also demonstrated differences across outfield players with forwards having greater estimated body fat values than defenders (35) although there is generally little difference among the different outfield positions $(20,24)$. The present study was the first to compare body composition according to six positional roles. Results showed that in midfielders, mean body fat and mass values in players with a central and lateral role differed substantially. This finding is noteworthy and suggests that when mean body composition values are assessed across teams, data should be interpreted according to individual positional role and not to a traditional or basic division of four positional groups including goalkeepers, defenders, midfielders and attackers. Recent work on the analyses and interpretation of competitive work-rate performance in elite soccer has adopted this approach (3). On this basis, we can suggest 
that it would also be pertinent to compare other components of fitness in the profiling of athletic performance in the same way which up to now has not been achieved.

Body composition in soccer players is likely to change during the course of the competitive season as a result of training and competition, habitual activity and diet (23). In the present study, significant in-season differences were observed in fat-free mass values across all players with the changes linked to alterations in estimated body fat whereas body mass values did not vary. Interestingly, a significant increase in estimated body fat was observed between mid- and end-season points with the final value being similar to the pre-season value. We suggest that this finding can be explained by the tuning down of training intensity towards the end of the season leading to a fall-off in fitness measures $(2,29)$.

Importantly, the analysis of the 14 separate measures showed that the months in which the largest changes occurred (decreases and gains) in respective body fat, mass and fat-free mass varied considerably, It is therefore of interest to note that a change in body mass for example is not always a good indicator of a change in body composition and other parameters such as skinfold measurements should be used to provide supplementary information. Furthermore, this finding also suggests a need for continuous monitoring over the entire season, such as on a monthly basis (as achieved in the present study), rather than at a limited number of time points.

In general, these observations contradict the findings of Clarke et al. (7) and Aziz et al. (1) who did not find any significant intra-seasonal variation in estimated body fat or body mass from several measurements in professional English Premier 
League and Singapore players. Clarke and colleagues suggested that this discrepancy may have been down to the poor reliability of their data collection method (Bioelectric impedance analysis) whereas Aziz and colleagues suggested that the low level of preseason body fat in the Singapore players $(\sim 11 \%)$ could be a plausible reason.

The intra-season fluctuations in estimated body fat and free-fat mass were shown to vary across the four positional groups. We can therefore recommend that coaches take into account player positions when interpreting variations in body composition data across the season. However, no significant change was reported between the start and end of pre-season training across any of the positional groups. Previous studies have shown that there is a decreasing trend in body fat and mass across the season notably during the conditioning period $(21,23,37)$ which is mainly due to the body composition of professional soccer players during the off-season shifting towards to an excess fat condition (15). According to Reilly \& Peiser (29), the traditional picture for sports such as soccer was that the main training impulse was provided in the pre-season period. In the off-season, players became deconditioned, arrived for pre-season training with low fitness levels and responded to a rigorous training programme often conducted twice a day resulting in large decreases in estimated body fat. In this professional club, each player had a personal fitness and dietary regimen to follow during the off-season which probably ensured an adequate level of fitness when returning for pre-season training and which may provide a plausible reason for the lack of change in body fat after the preseason conditioning period. Another reasonable explanation for this discrepancy across studies could be the differences in the length and content of pre-season training. 
No significant inter-seasonal differences in estimated body fat or fat-free mass were observed suggesting that body composition profiles in the present players did not vary from one season to the next. In contrast, analyses of body composition in Japanese youth players reported significant differences in estimated body fat and fat-free mass across two seasons (35). According to Koutedakis (17) the swings in measures of fitness depend on the competitive level of the athlete. Aspects related to genetics, off-season activity, baseline fitness and appropriate training strategies (19) may also provide relevant explanations for the discrepancy between these two studies in soccer players of differing standards.

The examination of the relationship between exposure time to play and measures of body composition did not demonstrate any significant association. From this observation, we can suggest that variations in body composition across the season are perhaps more likely to be linked to the intensity or type of training undertaken, time off through injury, or perhaps to the density or importance of matches leading up to the taking of measures. A study on the effects of intense athletic training on fat patterning in runners showed that reductions in body fat across various regions of the body were specific to the muscular groups used during training (13). A more detailed examination of the relationship between training type, volume, intensity and frequency and measures of fitness as previously undertaken in elite rugby players (19) is therefore warranted.

The major strength of the present study was the availability of full-datasets and therefore repeated measurements obtained by the same physician for 26 players across 14 different points of the season and in 9 players over 3 consecutive seasons. Changes in player personnel due to both temporary and permanent inter-club transfers and player 
availability between test-to-test measurements tend to compromise repeated observations of body composition and fitness in elite soccer (7). To our knowledge, this is the first study to have reported repeated observations of body composition in players belonging to a top-class European soccer club over three entire competitive seasons. However, further research on a larger sample of players may be necessary to support the present findings.

There were two major weaknesses of the present study design. First, the limitations and possible errors in reporting measures (across studies) of body fat as a percentage rather than the sum of skinfolds, $(4,34)$ must be acknowledged. There is a problem in comparing the results across the literature due to the different methodologies and formulae employed. However, as the majority of the literature on body composition in elite soccer players traditionally expresses values as a percentage (26), the present values were also presented as percent body fat to allow comparison across studies.

Second, the limitations of the present equations used to estimate body fat in soccer players should be discussed. These equations have been based on measures undertaken in general populations and their validity for usage in soccer players has been questioned (34). Other equations such as the British Olympic Association's recommended method of using the sum of five skinfold sites (28) or the soccer-specific skinfold equation recently reported by Wallace and colleagues (36) may be more suitable methods of assessing body fat in soccer players.

PRACTICAL APPLICATIONS 
In elite soccer, mean body composition values are usually compared across four basic positional groups. A differentiation of measures according to individual positional role within these groups has not been achieved. In addition, there is limited knowledge on intra-seasonal variations in body composition across the playing season and the possible effects of positional group or exposure time to play on measures have not been investigated. The present study was the first to address these features.

Several novel findings were reported allowing us to make practical recommendations to aid in the analysis and interpretation of body composition data in professional soccer. First, to ensure an objective comparison of the data obtained from body composition analyses across a squad of professional soccer players, results should be interpreted according to the specific positional role of the player. Second, substantial variations in body composition occur in a squad of players at different points during a competitive season suggesting a need for continuous monitoring of this component of fitness across the entire season. Third, the analysis of data on intra-season variations in body composition should be extended to include the effects of individual positional group as this variable can influence both the timing and extent of variations in measures.

While this study has elicited useful results and allowed us to make several relevant recommendations, further work is needed to confirm whether the present advice could be applied in other populations such as elite youth and female soccer players. Nevertheless, it is hoped that coaches and sports scientists may use the present results as a tool for a better understanding of the role and interpretation of body 
composition measures as part of the fitness profiling of professional soccer players and as a means for identifying areas that require further exploration.

\section{ACKNOWLEDGMENTS}

The authors express their appreciation to the players for their involvement in this study. The authors have no conflicts of interest that are directly relevant to the content of this article. 


\section{REFERENCES}

1. Aziz, AR, Tan, FYH, and Teh, KC. Variation in Selected Fitness Attributes of Professional Soccer Players during a League Season. In: Science and Football V. Reilly, T, Cabri, J and Araújo, D, eds. London: Routledge, 2005. pp. 134-138.

2. Brady, K, Maile, A, and Ewing, B. An investigation into the fitness of professional soccer players over two seasons. In: Science and football III. Reilly T, Bangsbo, J and Hughes M, eds. London: E \& FN Spon, 1997. pp. 118-112.

3. Carling, C, Bloomfield, J, Nelsen, L, and Reilly T. The role of motion analysis in elite soccer: Contemporary performance measurement techniques and work-rate data. Sports Med 38: 839-862, 2008.

4. Carling, C, Reilly, T, and Williams, AM. Performance assessment for field sports. London, UK: Routledge, 2008.

5. Carling, C, Le Gall, F, Reilly, T, and Williams AM. Do anthropometric and fitness characteristics vary according to birth date distribution in elite youth academy soccer players? Scand J Med Sci Sports 7: 3-9, 2009.

6. Casajús, JA. Seasonal variation in fitness variables in professional soccer players. $J$ Sports Med Phys Fit 41: 463-467, 2001.

7. Clark, NA; Edwards, AM; Morton, RH, and Butterly, RJ. Season-to-season variations of physiological fitness within a squad of professional male soccer players J Sports Sci Med 7: 157-165, 2008.

8. Cohen J. Statistical power analysis for the behavioural sciences. 2nd ed. Hillsdale, NJ: Lawrence Erlbaum; 1988.

9. Diniz Da Silva, C, Bloomfield, J, and Bouzas Marins, JC. A review of stature, body mass and maximal oxygen uptake profiles of U17, U20 and first division players in Brazilian soccer. J Sports Sci Med 7, 309-319, 2008. 
10. Dunbar G, Power K. Fitness profiles of English professional and semi professional soccer players using a battery of field tests. In: Science and football III. Reilly T, Bangsbo J, Hughes M, eds. London: E \& FN Spon, 1997. pp. 27-31.

11. Durnin, JVGR, and Wormersley J. Body fat assessed from total body density and its estimation from skinfold thickness: measurements on 481 men and women aged from 16 to 72 years. Bri J Nutr 32: 77-97, 1974.

12. Duthie, GM, Pyne, DB, and Hooper, S. The applied physiology and game analysis of rugby union. Sports Med 33: 973-91, 2003.

13. Gabbett, T, and Domrow, N. Relationships between training load, injury, and fitness in sub-elite collision sport athletes. J Sports Sci 25: 1507-1519, 2007.

14. Gil, SM, Gil, J, Ruiz, F, Irazusta, A, and Irazusta J. Selection of young soccer players in terms of anthropometric and physiological factors. J Sports Med Phys Fit 47: 25-32, 2007.

15. Hoshikawa, Y, Kanno, A, Ikoma, T, Muramatsu, M, Iida, T, Uchiyama, A, and Nakajima, Y. Off-season and pre-season changes in total and regional body composition in Japanese professional soccer league players In: Science and Football V. Reilly, T, Cabri, J, and Araújo, D, eds. London: Routledge, 2005. pp. 160-165.

16. International Society for the Advancement of Kinanthropometry. International standards for anthropometric assessment. North West University (Potchefstroom Campus), Potchefstroom 2520, South Africa: ISAK (revised 2006), 2001.

17. Koutedakis, Y. Seasonal variation in fitness parameters in competitive athletes. Sports Med 19: 373-92, 1995.

18. Kutlu, M, Sofi, N, and Bozkus, T. Changes in body compositions of elite level amateur and professional soccer players during the competitive season. J Sports Sci Med 7: 53, 2007. 
19. Legaz, A, and Eston R. Changes in performance, skinfold thicknesses, and fat patterning after three years of intense athletic conditioning in high level runners Bri J Sports Med 39: 851-856, 2005.

20. Matkovic, BR. Misigoj-Durakovic, M, Matkovic, B, Jankovic, S, Ruzic, L, Leko, G, and Kondric, M. Morphological differences of elite Croatian soccer players according to the team position. Coll Antropol 7 (Suppl 1):167-74, 2003.

21. Mercer, TH, Gleeson, NP, and Mitchell, J. (1995) Fitness profiles of professional soccer players before and after pre-season conditioning. In: Science and football III. Reilly, T, Bangsbo, J, and Hughes, M, eds. London: E \& FN Spon, 1997. pp. 112117.

22. Norton, K., Marfell-Jones, M., Whittingham, N., Kerr, D., Carter, L., Saddington, K., and Gore, C. (2000) Anthropometric Assessment Protocols. In: Physiological Tests for Elite Athletes: Australian Sports Commission. Gore, CJ. ed. pp. 66-85.

23. Ostojic, SM. Seasonal alterations in body composition and sprint performance of elite soccer players. J Exerc Phys 6, 11-14, 2003.

24. Ramadan, J, and Byrd, R. Physical characteristics of elite soccer players. J Sports Med Phys Fitness 27: 424-8, 1987.

25. Reilly T. Fitness assessment. In: Science and Soccer. Reilly, T, ed. London: E \& FN Spon, 1996. pp. 25-49.

26. Reilly, T. The science of training - soccer. London, UK: Routledge, 2008.

27. Reilly, T, Bangsbo, J, and Franks A. Anthropometric and physiological predispositions for elite soccer. J Sports Sci 18: 669-683, 2000.

28. Reilly, T, Maughan, RJ, and Hardy, L. Body fat consensus statement of the steering groups of the British Olympic Association. Sports Exerc Inj 2: 46-49, 1996. 
29. Reilly, T, and Peiser, B. Seasonal Variations in Health-Related Human Physical Activity. Sports Med 36: 473-85, 2006.

30. Reilly, T, Williams, AM, Nevill, A, and Franks, A. A multidisciplinary approach to talent identification in soccer. J Sports Sci 18: 695-702, 2000.

31. Siri WE. Body composition from fluid spaces and density: analysis of methods. In: Techniques for Measuring Body Composition. Brozeck J and Henschel A eds. Washington, DC: National Academy of Sciences, 1961.pp. 223-244.

32. Stewart, A, and Eston, RG. (2006) Surface Anthropometry. In: Sport and Exercise Physiology Testing: Guidelines. Volume I Sport Testing. Winter, EM, Jones, AM, Davison, RCR, Bromley PD and Mercer, TH. (eds). London: Routledge. pp. 76-83.

33. Stølen, T, Chamari, K, Castagna, C, and Wisløff, U. Physiology of soccer: an update. Sports Med 35: 501-36, 2005.

34. Sutton, L, Scott, M, and Reilly, T. Validation of a new anthropometric equation for the prediction of body composition in elite soccer players. In: Proceedings of the $1^{\text {st }}$ World Conference on Science and Soccer. Liverpool, UK, 15-16 May, 2008. 2008, 77.

35. Tahara, Y, Moji, K, Tsunawake, N, Fukuda, R, Nakayama, M, Nakagaichi, M, Komine, T, Kusano, Y, Aoyagi, K. Physique, body composition and maximum oxygen consumption of selected soccer players of Kunimi High School, Nagasaki, Japan. J Physiol Anthropol 25: 291-297, 2006.

36. Thomas, V, and Reilly T. Fitness assessment of English league soccer players through the competitive season. Brit J Sports Med 13: 103-109, 1979.

37. Wallace, J, Billows, D, George, K, and Reilly, T. Bone mineral density and body composition changes during a Premier League association football season. J Sports Sci Med 7: 53-54, 2007. 


\section{FIGURE LEGENDS}

Figure 1. Comparison of mean estimated body fat values across six positional roles in professional soccer players $(\mathrm{n}=26)$.

Figure 2. Variation in mean pre- and end-season percent body fat values over three consecutive seasons in professional soccer players $(n=9)$. 
Figure 1.

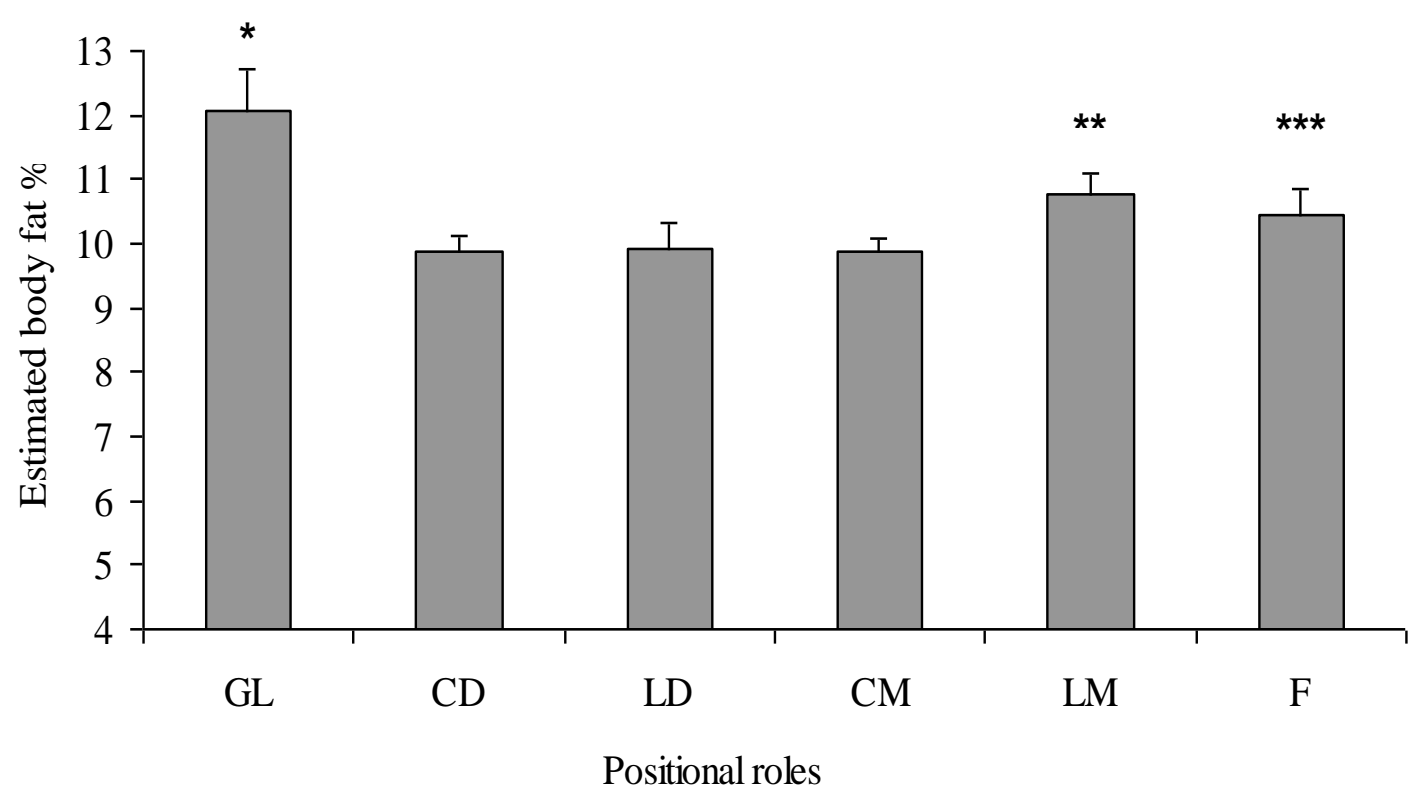

$\mathrm{GL}=$ goalkeeper, $\mathrm{CD}=$ central-defender, $\mathrm{LD}=$ lateral-defender, $\mathrm{CM}=$ central-midfielder, $\mathrm{LM}=$ lateralmidfielders, $\mathrm{F}=$ forward.

* Significant difference versus all positional roles, $\mathrm{p}<0.001$

** Significant difference versus LD, CD and CM, p $<0.001$

*** Significant difference versus CD and CM, $\mathrm{p}<0.01$ 
Figure 2.

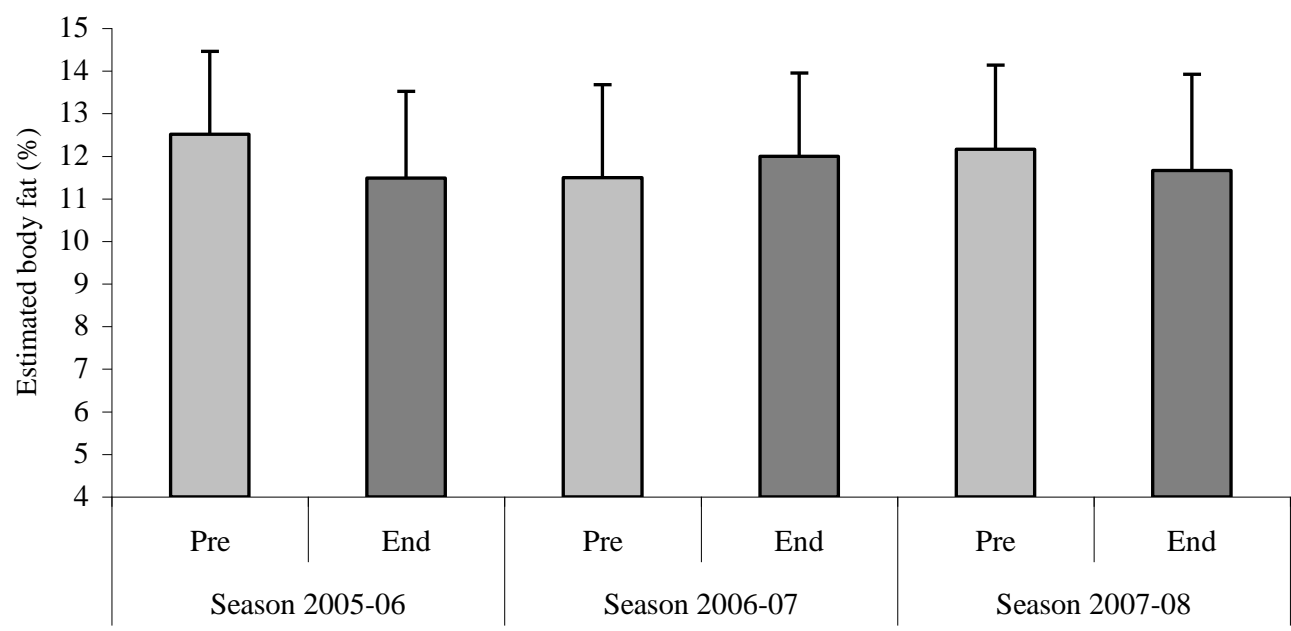


Table 1. Percent body fat, mass, fat-free mass in professional soccer players according

to four playing positions at five different points across the season $(n=26)$.

\begin{tabular}{|c|c|c|c|c|c|c|c|}
\hline & SPS & EPS & MS & EMSB & ES & Significance & Post hoc \\
\hline \multicolumn{8}{|l|}{ Body Fat (\%) } \\
\hline All players & $10.81 \pm 1.77$ & $10.45 \pm 1.61$ & $10.19 \pm 1.75$ & $10.23 \pm 1.52$ & $10.80 \pm 1.63$ & $\mathrm{p}<0.001$ & SPS vs MS. ES v MS \\
\hline Goalkeepers & $11.63 \pm 2.96$ & $12.67 \pm 2.51$ & $11.68 \pm 3.28$ & $10.27 \pm 2.25$ & $12.28 \pm 2.79$ & $\mathrm{p}=0.042$ & \\
\hline Defenders & $10.66 \pm 2.09$ & $10.11 \pm 1.92$ & $10.16 \pm 2.00$ & $10.41 \pm 2.07$ & $10.53 \pm 1.83$ & $\mathrm{p}=0.093$ & \\
\hline Midfielders & $10.34 \pm 0.83$ & $9.99 \pm 0.85$ & $9.51 \pm 0.90$ & $9.76 \pm 0.89$ & $10.40 \pm 1.01$ & $\mathrm{p}=0.002$ & SPS vs MS. ES vs MS \\
\hline Forwards & $10.50 \pm 1.01$ & $11.22 \pm 1.49$ & $10.30 \pm 0.53$ & $10.87 \pm 0.71$ & $10.76 \pm 0.45$ & $\mathrm{p}=0.502$ & \\
\hline \multicolumn{8}{|l|}{ Body mass (kg) } \\
\hline All players & $77.48 \pm 6.04$ & $77.52 \pm 6.19$ & $77.73 \pm 6.33$ & $77.45 \pm 6.34$ & $78.49 \pm 6.34$ & $\mathrm{p}=0.071$ & \\
\hline Goalkeepers & $81.75 \pm 3.81$ & $83.80 \pm 3.08$ & $83.33 \pm 4.73$ & $81.47 \pm 4.01$ & $83.28 \pm 3.46$ & $\mathrm{p}=0.931$ & \\
\hline Defenders & $77.84 \pm 5.32$ & $78.43 \pm 4.94$ & $78.60 \pm 6.01$ & $78.81 \pm 6.31$ & $79.53 \pm 5.66$ & $\mathrm{p}=0.059$ & \\
\hline Midfielders & $74.04 \pm 6.19$ & $74.37 \pm 6.14$ & $75.19 \pm 6.65$ & $74.27 \pm 6.02$ & $74.62 \pm 6.23$ & $\mathrm{p}=0.291$ & \\
\hline Forwards & $79.60 \pm 6.57$ & $78.10 \pm 7.60$ & $77.70 \pm 6.09$ & $77.67 \pm 8.43$ & $79.96 \pm 6.88$ & $\mathrm{p}=0.414$ & \\
\hline \multicolumn{8}{|c|}{ Free-fat mass $(\mathrm{kg})$} \\
\hline All players & $69.11 \pm 5.43$ & $69.41 \pm 5.53$ & $70.10 \pm 5.67$ & $69.52 \pm 5.64$ & $70.00 \pm 5.56$ & $\mathrm{p}<0.001$ & MS vs SPS. ES vs SPS \\
\hline Goalkeepers & $72.20 \pm 2.69$ & $73.15 \pm 1.97$ & $73.10 \pm 2.47$ & $73.04 \pm 1.76$ & $72.99 \pm 1.69$ & $\mathrm{p}=0.546$ & \\
\hline Defenders & $69.54 \pm 5.02$ & $70.50 \pm 4.69$ & $70.62 \pm 5.53$ & $70.61 \pm 5.82$ & $71.18 \pm 5.53$ & $\mathrm{p}=0.008$ & ES vs SPS \\
\hline Midfielders & $66.38 \pm 5.59$ & $66.96 \pm 5.80$ & $68.06 \pm 6.37$ & $67.04 \pm 5.72$ & $66.87 \pm 5.74$ & $\mathrm{p}=0.009$ & MS vs SPS \\
\hline Forwards & $70.72 \pm 6.63$ & $69.94 \pm 7.35$ & $70.08 \pm 6.31$ & $69.22 \pm 7.42$ & $71.35 \pm 5.97$ & $\mathrm{p}=0.859$ & \\
\hline
\end{tabular}

Data are mean \pm SD

SPS=Start of pre-season training. EPS=End of pre-season training. MS=Mid-season. EMSB=End of mid-season break. ES=End of season. 